\title{
The Culturally Responsive Teacher Preparedness Scale: An Exploratory Study
}

\author{
Yun-Ju Hsiao, Washington State University Tri-Cities, USA
}

\begin{abstract}
The purpose of this study was to investigate the competencies of culturally responsive teaching and construct a Culturally Responsive Teacher Preparedness Scale (CRTPS) for the use of teacher preparation programs and preservice teachers. Competencies listed in the scale were identified through literature reviews and input from experts. The preparedness scale was created through an exploratory factor analysis. According to the factor analysis, there were three factors for CRTPS: curriculum and instruction, relationship and expectation establishment, and group belonging formation. The scale is well supported by psychometric analysis including factor loadings, internal consistency, and testing fairness with gender and race. Limitations and conclusions were made for the use of this scale.
\end{abstract}

Keywords: Culturally Responsive Teacher; Culturally Responsive Teaching; Multicultural Education; Teacher Education

\section{INTRODUCTION}

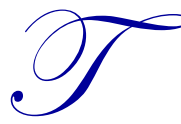

he United States of America is comprised of different races and ethnicities. As a result, it has diverse cultures. The student population of the United States is not an exception to cultural diversity either (Samuels, 2007). Therefore, educating culturally diverse students has become one of the vital issues in education. It has been indicated that teachers' knowledge, beliefs, and attitudes are highly correlated with students' races, ethnicities, and the qualities of education that they receive (Gay, 2002a). In order to successfully teach students from culturally and linguistically diverse backgrounds, culturally responsive teaching, as an equitable and culturally sensitive instruction practice, has been advocated by many scholars and organizations (Gay, 2002a; National Council for Accreditation of Teacher Education, 2008; Siwatu, 2007; Wlodkowski, 1999). If teachers can understand students' backgrounds and teach in a culturally responsive way, several critical educational problems might be alleviated, such as low academic achievement and the disproportionate representation in special education (Blanchett, 2006; Gay, 2002a). That is, implementing culturally responsive teaching does not only improve academic achievement of diverse students (Gay 2002a; Plata 2008), but also benefit all students (Barnes, 2006; Plata, 2008).

Being responsive means reacting appropriately in the instructional context (Irvine \& Armento, 2001). Bowers and Flinders (as quoted in Irvine \& Armento, 2001, p. 5) also proposed that "being responsive means to be aware of and capable of responding in educationally constructive ways to the ways in which cultural patterns influence the behavioral and mental ecology of the classroom." Cultural responsiveness could represent all aspects of the above concepts, and also include the meaning of connection between home or community culture and school culture (Pewewardy \& Hammer, 2003). Therefore, the term, cultural responsiveness is used in this study. Gay (2002a, p. 619) proposed that "[c]ulturally responsive teaching is a comprehensive endeavor that is engendered in all dimensions of the educational enterprise, including diagnosing students' needs, curriculum content, counseling and guidance, instructional strategies, and performance assessment." A number of scholars have emphasized the need of cultivating preservice teachers to acquire culturally responsive teaching competencies in teacher preparation programs (Gay, 2005; Spanierman et al., 2011).

Since culturally responsive teaching is a teaching pedagogy that teachers can implement in their classrooms to instruct their students from different cultural backgrounds, various frameworks are used as bases to classify the culturally responsive teaching competencies. Usually, researchers use categories, components, domains, aspects or 
major competencies to organize culturally responsive teaching competencies (Gay, 2002b; Hollins, 1993; Siwatu, 2006). Under a specific framework, researchers list some competencies to describe the ability of culturally responsive teachers more clearly, and thus can help teachers to be familiar with implementing culturally responsive teaching.

Hollins (1993) reviewed four seminal studies in order to create a knowledge base to identify teacher behaviors or actions that can improve learning of diverse students. According to the analysis of the reviewed literature, she suggested that there are seven specific competencies for teaching diverse populations: (a) communicating with diverse learners, (b) knowing subject and students, (c) reflective teaching, (d) identifying resources, (e) creating a supportive context, (f) developing interpersonal relationships, and (g) promoting learner performance. Gay (2002b) expanded these competencies to include: (a) developing a cultural diversity knowledge base, (b) designing culturally relevant curricula, (c) demonstrating cultural caring, (d) building a learning community, (e) establishing cross-cultural communications, and (f) establishing cultural congruity in classroom instruction. However, Siwatu (2006) grouped the culturally responsive teaching competencies into four categories: (a) curriculum and instruction, (b) classroom management, (c) student assessment, and (d) cultural enrichment. He presented competencies derived from theoretical discussions and quantitative and qualitative studies that documented the practices of culturally responsive teachers. Under the four categories, he put forth a total of 29 competencies.

From aforementioned literature, Gay (2002b) separated culturally responsive curriculum and instruction into different domains, while Siwatu (2006) combined them together as one category (curriculum and instruction). Hollins' (1993) knowing subjects, engaging in reflective teaching, and identifying resources could be considered as design of curriculum and instruction. Moreover, all of them proposed that creating a caring environment and supporting students were important elements of culturally responsive teaching. Both Gay (2002b) and Hollins (1993) put forth communication as one specific category. Besides, developing a cultural diversity knowledge base (Gay, 2002b), developing interpersonal relationship (Hollins, 1993), managing classroom and assessing students (Siwatu, 2007) are also viewed as important elements of culturally responsive teaching.

Many efforts, through employing qualitative and quantitative methods, have advanced the assessment of culturally responsive teaching competencies for preservice and inservice teachers (Spanierman et al., 2011). These methods include observations of classroom teaching, parent and/or student ratings of teachers, focus group discussions, and survey of preservice teachers. For example, Stanley (1996) developed an instrument, the Pluralism and Diversity Attitude Assessment, to assess preservice teachers' attitude toward diverse students. Spanierman et al. (2011) used a psychometrical method to develop a self-report scale for assessing teachers' culturally responsive competencies. Spanierman et al. (2011) found that the tripartite model, which included multicultural belief/attitude, knowledge, and skill competencies developed by Sue et al. (1982), was reduced to two constructs: knowledge and skills. That is, they did not find multicultural teaching awareness to be a viable factor to assess teachers' culturally responsive competencies.

Although previous studies clearly identify culturally responsive teaching competencies for preservice teachers and develop several scales to evaluate how preservice teachers possess these competencies, to the researcher's knowledge no psychometric scale was developed to evaluate the level of preparedness perceived by preservice teachers for culturally responsive teaching. Since multiple methods used to access students' competencies for culturally responsive teaching could help teacher preparation programs understand their effectiveness in training teachers from different aspects (Spanierman et al., 2011) and improve their programs, the purpose of this study was to develop a multidimensional scale to examine preservice teachers' sense of preparedness to execute the practices associated with culturally responsive teaching. The definition of culturally responsive teachers for this study is the preservice teachers who will be culturally responsive in their classroom instruction to their diverse students, including identifying students' needs, communicating with students and parents, designing and implementing curricula and teaching, creating a caring and supporting setting and enriching students' diverse cultures. There are two research questions for the current study:

1. What are the main factors of the Culturally Responsive Teacher Preparedness Scale (CRTPS)?

2. Does the CRTPS meet the general requirement of testing fairness with race and gender? 
The first research question is to examine the constructs of CRTPS while the second research question is to initially validate if the scale meets the general requirement of testing fairness with race and gender (American Educational Research Association, American psychological Association, \& National Council on Measurement in Education, 1999).

\section{METHOD}

This study uses a survey method to collect data and an exploratory factor analysis to explore the underlying constructs of the various identified competencies in developing a preparedness scale and further validates estimates of the scale across comparison groups.

\section{Participants}

Participants were recruited from teacher education programs at two universities in the southwestern region of the United States. Initially, a total of 188 teacher education students (preservice teachers) who enrolled in their final semester participated in the study (77 students from one university, and 111 students form the other university). At their final period of the classes, the researcher distributed the questionnaire to students to rate their preparedness level for culturally responsive teaching. After the survey, one returned questionnaire with seven items omitted was dropped from the data analysis procedure and yielded a total of 187 surveys for sample validation with a return rate of $99.5 \%$.

There were 56 participants $(29.9 \%)$ in the elementary education program, 102 participants $(54.5 \%)$ in the special education program, 16 participants $(8.6 \%)$ in early childhood education, and 12 participants $(6.4 \%)$ in early childhood special education. One participant did not indicate which program he/she enrolled in. Among these participants, $160(85.6 \%)$ were female and $27(14.4 \%)$ were male. The age range of the participants was from 20 to 64 years old, with a mean age of $29.7(\mathrm{SD}=9.35)$. One hundred and forty-one participants $(75.4 \%)$ were Caucasian/White, 17 (9.1\%) were Hispanic, 8 (4.3\%) were Black/African American, 4 (2.1\%) were Asian, and 3 (1.6\%) were Native Hawaiian/Other Pacific Islander, 1 (.5\%) was American Indian/Alaskan, 12(6.4\%) were biracial or multiracial, and $1(.5 \%)$ did not report his/her racial background.

\section{Instrumentation}

The survey instrument was divided into two sections. The first section included 32 culturally responsive teaching competencies refined from the literature. The second section contained questions about background information used to collect demographic data.

The instrument used four aspects to identify competencies. These aspects were: (a) curriculum and instruction, (b) classroom management, (c) student assessment, and (d) cultural enrichment (Siwatu, 2006). Articles chosen and used to development the instrument included works of Gay (2002b), Hollins (1993), Rodriguez and Sjostrom (1996), and Siwatu (2006, 2007). It is important to note that these four categories were listed as broad categories rather than an exhaustive list.

To determine if the instrument measures what it intended to measure, the validity of the instrument is important. In order to examine if the competencies listed were suitable in the survey, the initial draft of the questionnaire was reviewed by a professor in special education whose expertise was in teaching culturally and linguistically diverse students and multicultural education. The revised draft of questionnaire was given to three other professors in the field of teacher education: One is an associate division director for an Initial Teacher Certification Program, another is a director of a Special Education Program, and the other is a coordinator of an Elementary Education Partnership Program. After receiving the comments and suggestions from these three experts, items that were ambiguous were rewritten to clarify their meaning to ensure the content validity. A total of 32 competencies were identified in the questionnaire. The competencies were rated on a 6-point Likert scale, ranging from unprepared to fully prepared, respectively. Participants were guided to self-rate each competency to indicate their preparedness. Each competency had the same stem "I am able to" and asked about competency contents, such as "communicate expectations of success to culturally diverse students," "infuse the curriculum and thematic units 
with the culture of students represented in the classroom," and "create a warm, supporting, safe, and secure classroom environment for culturally diverse students."

\section{Data Collection and Analysis Procedures}

After the questionnaire items were identified and the protocol for Institution Review Board was approved, data were collected in preservice teacher education classes. The students completed the questionnaire during the beginning or the last 15 minutes of their final period of the class in their final semester for teacher preparation programs. The questionnaires were used for the factor analysis.

Factor analysis is used to "identify the factor structure or model for a set of variables" (Henson \& Roberts 2006, p. 395). An exploratory factor analysis was applied, since the purpose of this study was to develop a CRTPS for the use of teacher preparation programs and preservice teachers. The following rules were applied to decide if the survey items were retained or not as variables. First, item communality is greater than .50 to suffice sample size requirement (Worthington \& Whittaker, 2006). Second, item loadings need to exceed .50 on at least one factor and cross loading items with values less than .32 (Costello \& Osborne, 2005). Multiple criteria (Eigenvalue greater than one, scree test, and a factor with at least three items) were used to determine the number of factors to rotate (Henson \& Roberts, 2006). An oblique rotation with principal component analysis was performed, since these factors were assumed to be correlated (Costello \& Osborne, 2005). In addition, the categories, components or aspects of these competencies from literature were used as references to name the underlying factor structure after the factor analysis. Independent $t$ tests were used to test the score differences for race and gender.

\section{RESULTS}

Before factor analysis, Kaiser-Meyer-Olkin (KMO) and Bartlett's Test were analyzed. The value of KMO was .940 , and sig. $=.00$; therefore, it was appropriate to conduct a factor analysis. The dimensionality of the 32 items from the survey instrument was analyzed by using a principal components analysis. Items that did not meet aforementioned rules were deleted. After applying the rules of the factor's Eigenvalue greater than one, the "elbow" in the scree plot, and a factor with at least three items, the researcher decided to extract three interpretable factors for the scale, which were also consistent with initial conceptualization of four-aspect model. These three factors are as follows: curriculum and instruction (factor 1), relationship and expectation establishment (factor 2), and group belonging formation (factor 3). A total of 18 items remains in the scale. Factor loadings and communalities for each item are shown in table 1 . A total of four factors accounted for $69.73 \%$ of the item variance. Each factor has a variance of $53.70 \%, 8.81 \%$, and $7.22 \%$, respectively. 
Table 1. Factor Loadings and Communalities for the Culturally Responsive Teacher Preparedness Scale.

\begin{tabular}{|c|c|c|c|c|}
\hline Items & & omponen & & $h^{2}$ \\
\hline I am able to: & Factor 1 & Factor 2 & Factor 3 & \\
\hline $\begin{array}{l}\text { 1. infuse the curriculum and thematic units with the } \\
\text { culture of students represented in the classroom. }\end{array}$ & .913 & .133 & .036 & .695 \\
\hline $\begin{array}{l}\text { 2. review and assess curricula and instructional } \\
\text { materials to determine their multicultural } \\
\text { strengths and weakness, and relevance to } \\
\text { students' interest and instructional needs, and } \\
\text { revise them if necessary. }\end{array}$ & .804 & .023 & .002 & .626 \\
\hline $\begin{array}{l}\text { 3. develop a repertoire of instructional examples } \\
\text { that are culturally familiar to students to serve as } \\
\text { a scaffold for learning. }\end{array}$ & .761 & -.022 & -.060 & .647 \\
\hline $\begin{array}{l}\text { 4. find ways to support language acquisition and } \\
\text { enhance culturally and linguistically diverse } \\
\text { students' comprehension of classroom tasks }\end{array}$ & .711 & -.257 & .218 & .607 \\
\hline $\begin{array}{l}\text { 5. use a variety of assessment techniques, such as } \\
\text { self-assessment, portfolios, and so on, to evaluate } \\
\text { students' performance in favor of cultural } \\
\text { diversity. }\end{array}$ & .698 & .031 & -.245 & .684 \\
\hline $\begin{array}{l}\text { 6. design assessments to complement the culturally } \\
\text { responsive pedagogical strategies that were } \\
\text { employed during instruction. }\end{array}$ & .643 & -.084 & -.192 & .653 \\
\hline $\begin{array}{l}\text { 7. assess culturally diverse students' readiness, } \\
\text { intellectual and academic strengths and } \\
\text { weaknesses, and development needs. }\end{array}$ & .559 & -.211 & -.185 & .658 \\
\hline $\begin{array}{l}\text { 8. utilize a variety of instructional methods to } \\
\text { match students' learning preferences in learning } \\
\text { the subject matter, and maintaining their } \\
\text { attention and interest in learning. }\end{array}$ & .551 & -.173 & -.159 & .574 \\
\hline $\begin{array}{l}\text { 9. know how to communicate with culturally } \\
\text { diverse students and their parents or guardians. }\end{array}$ & .024 & -.925 & .107 & .789 \\
\hline $\begin{array}{l}\text { 10. structure classroom-based meetings that are } \\
\text { comfortable for parents. }\end{array}$ & -.087 & -.921 & -.050 & .815 \\
\hline $\begin{array}{l}\text { 11. foster meaningful and supportive relationships } \\
\text { with parents and families, and actively involve } \\
\text { them in their students' learning. }\end{array}$ & -.075 & -.811 & -.200 & .787 \\
\hline $\begin{array}{l}\text { 12. use non-traditional discourse styles with } \\
\text { culturally diverse students in an attempt to } \\
\text { communicate in culturally responsive ways. }\end{array}$ & .303 & -.616 & .005 & .667 \\
\hline $\begin{array}{l}\text { 13. communicate expectations of success to } \\
\text { culturally diverse students. }\end{array}$ & .251 & -.513 & -.182 & .636 \\
\hline $\begin{array}{l}\text { 14. establish expectations for appropriate classroom } \\
\text { behavior in considering students' cultural } \\
\text { backgrounds to maintain a conducive learning } \\
\text { environment. }\end{array}$ & .186 & -.503 & -.303 & .688 \\
\hline $\begin{array}{l}\text { 15. develop and maintain positive, meaningful, } \\
\text { caring, and trusting relationships with students. }\end{array}$ & -.065 & -.086 & -.898 & .832 \\
\hline $\begin{array}{l}\text { 16. create a warm, supporting, safe, and secure } \\
\text { classroom environment for culturally diverse } \\
\text { students. }\end{array}$ & .011 & -.054 & -.885 & .844 \\
\hline $\begin{array}{l}\text { 17. create a community of learners by encouraging } \\
\text { students to focus on collective work, } \\
\text { responsibility, and cooperation. }\end{array}$ & .086 & -.054 & -.819 & .799 \\
\hline $\begin{array}{l}\text { 18. provide students with knowledge and skills } \\
\text { needed to function in mainstream culture. }\end{array}$ & .315 & .005 & -.537 & .549 \\
\hline
\end{tabular}


The value of factor loading of each item for the first factor (item 1 to 8), curriculum and instruction, ranged from .551 to .913 . The value of communality of each item for this factor ranged from .574 to .695 . The values of factor loadings of competencies for the second factor (item 9 to 14), relationship and expectation establishment, ranged from .503 to .925 . The communalities of competencies in this factor ranged from .636 to .815. In the third factor (item 15 to 18), group belonging formation, the highest factor loading is .898 , and the lowest .537 . The communalities of competencies in this factor ranged from .549 to .844. In sum, the values of factor loadings of competencies for factors in the whole survey ranged from .503 to .925 ; while the values of communalities of competencies for factors in the whole survey ranged from .549 to .844 .

As for internal consistency estimation of reliability, the Cronbach's alpha was computed for the whole survey instrument and each factor of the survey instrument. Value for Cronbach's alpha for the whole survey was .95; values for Cronbach's alpha of the three factors were $.91, .91$, and .88 , respectively. The results indicated that there were high reliabilities for the whole survey instrument and the three factors (Field, 2009).

In order to examine testing fairness for race and gender, independent $t$ tests were used to test the score differences. The results indicated that scores between male students and female students on the scale were not significantly different $\left(M_{\text {male }}=83.15, S D_{\text {male }}=14.84, n=27\right.$, vs. $M_{\text {female }}=83.32, S D_{\text {female }}=14.43, n=160, t=-.06, p$ $=.96)$. In addition, scores between white students and non-white students were not significantly different $\left(M_{\text {white }}=\right.$ 83.25, $S D_{\text {white }}=14.93, n=141$, vs. $M_{\text {non }}=83.24, S D_{\text {non }}=13.12, n=45, t=.00, p=.99$ ). The results indicated that the scores of culturally responsive teacher preparedness scale perceived by preservice teachers were not different in terms of race and gender.

\section{DISCUSSION}

The purpose of this study was to provide initial psychometric support of the preparedness scale of culturally responsive teaching to be used with teacher preparation programs and preservice teachers. Results from factor analysis and internal consistency supported three subscales that are consistent with the initial conceptualization of culturally responsive teaching literature. According to the factor analysis, culturally responsive teacher preparedness scale can be categorized into three factors: (a) curriculum and instruction, (b) relationship and expectation establishment, and (c) group belonging formation. Results are consistent with culturally responsive teaching literature. Because advocates approach culturally responsive teaching competencies from different directions or interpretations, it is difficult to compare them with or integrate them into factors identified in this study on the basis of a one-to-one comparison. However, a general rather than exhaustive comparison can still be made in terms of the broad meanings or interpretations of competencies identified by advocates.

The first factor of the scale, curriculum and instruction, combine two factors, curriculum and instruction and student assessment, which are advocated by Siwatu (2006). It is not surprising that factors separated by the fourfactor model are integrated into a factor in this scale. It is well known that before, during, and after teaching, student assessment is important for modifying, adapting, improving and designing curriculum and instruction. Before teaching, teachers need to know culturally diverse students' readiness, intellectual and academic strengths and weaknesses, and development needs; during teaching, teachers need to design assessments to complement the culturally responsive pedagogical strategies that were employed; and after teaching, teachers need to use a variety of assessment techniques (e.g., self-assessment, portfolios) to evaluate students' performance in support of cultural diversity. In terms of curriculum, teachers need to review and assess curricula and instructional materials to determine their multicultural strengths and weakness and the relevance to students' interest and instructional needs, revise them if necessary, and infuse them with the culture of students represented in the classroom. For instruction, teachers need to utilize a variety of instructional methods, develop a repertoire of instructional examples, and find ways to support language acquisition to match students' learning preferences in learning the subject matter, and maintaining their attention and interest in learning. This factor has the highest prediction variance in the scale to evaluate teachers for culturally responsive teaching. This factor includes the areas discussed by Hollins (1993): (a) knowing the subject and students, (b) engaging in reflective teaching, (c) identifying resources, and (d) promoting learners performance. The factors of designing culturally relevant curricula and establishing cultural congruity in classroom instruction (Gay 2002b) are also included. 
The factor of relationship and expectation establishment in this study is mainly focused on communication with parents or families so as to foster their involvement in students' learning and expectations of success for students. Therefore, communicating with parents, structuring meetings that make parents feel comfortable, fostering supportive relationships with parents and families, and establishing expectations for students to maintain a conducive learning environment are important competencies to recognize preservice teachers' preparedness for culturally responsive teaching. This factor is extracted from the classroom management factor of four-factor model. However, it is more clearly to indicate that for culturally responsive teaching, the relationship and expectation establishment through communication with parents and students plays a major role for classroom management in culturally responsive teaching. One of Hollins' (1993) major competencies, developing interpersonal relationships, also includes this important factor.

The factor of group belonging formation is important for culturally responsive teaching because it emphasizes on creating a warm, supporting, safe, and secure classroom to maintain positive, meaningful, caring, and trusting relationships with culturally diverse students, as well as providing knowledge and skills for students to function in mainstream culture focusing on collective work, responsibility, and cooperation. This again echoes the work of Hollins' (1993) creating a supportive context, Gay's (2002b) cultural caring for students and building a learning community, and Siwatu's (2006) classroom management and cultural enrichment.

The scores of CRTPS perceived by preservice teachers are no differences in race and gender. The scale has met the general requirements of testing fairness (American Educational Research Association, American psychological Association, and National Council on Measurement in Education, 1999).

\section{Limitations}

There are several limitations to this study. Samples used in this study were recruited from teacher preparation programs of two universities; this may restrict the generalization of the results to future teachers cultivated in other universities. Although the scores of CRTPS perceived by preservice teachers were no differences between white students and non-white students, fairness testing among subgroups (e.g., Hispanic, Black/African American, etc.) was not made in this study due to the low number of students in the subgroups. This needs to be further examined. In addition, this study used exploratory factor analysis to construct the scale; the future study is needed to use confirmatory factor analysis for further validation of the scale. Several related scales, such as the multicultural teaching competency scale developed by Spanierman et al. (2011), and preservice teachers' culturally responsive teaching self-efficacy scale developed by Siwatu (2006), may be used to further test criteria related validity for this scale.

The other limitation to this study is that the scores of CRTPS perceived by preservice teachers may not reflect their real ability to implement culturally responsive teaching or to teach culturally and linguistically diverse students. Because this scale used self-report method to investigate how preservice teachers thought they were prepared in culturally responsive teaching, it was possible that the participants could perceive their competencies with social desirability rather than with their real ability. Additional evidence for preservice teachers' preparedness of culturally responsive teaching from other sources is needed, such as, observations, structured interviews, or diary methods.

Finally, the competency preparedness for culturally responsive teaching analyzed in this study was based on the general competencies of culturally responsive teaching. That is, competency preparedness for specific subject matter (e.g., math, science, reading) is not specified in this study. Teachers have higher scores in this scale may not be good at teaching certain subject matters. More specific competencies about subject matters for evaluating teacher preparedness for classroom teaching are needed.

\section{CONCLUSIONS}

The initial psychometrical support of CRTPS was constructed in this study. The three-factor scale revealed in this study: (a) curriculum and instruction, (b) relationship and expectation establishment, and (c) group belonging formation, provides a starting point for teacher preparation programs to understand their students' preparedness for 
working with diverse students. Students may also use this scale to evaluate their preparedness to teach in a diverse classroom. In addition, since the population of culturally and linguistically diverse students continues to increase, there is a definite need for developing the competence of culturally responsive teachers. The factors identified in the present study can be used as constructs for teacher education programs to prepare future teachers. Teacher education students may use these competencies as a guide to elect courses related to culturally responsive teaching. Also, the factors and competencies can provide current teachers a roadmap to use as they work with students from diverse group in education. Furthermore, researchers can use these three factors as a competency framework to discuss the characteristics of culturally responsive teaching and thus develop a more comprehensive and detailed system for culturally responsive teaching.

\section{AUTHOR INFORMATION}

Yun-Ju Hsiao, Ph.D. is an Assistant Professor of Special Education in the Department of Teaching and Learning at Washington State University Tri-Cities. Her research interests include families of students with disabilities, evidence-based instructional strategies for students with autism spectrum disorders, and culturally responsive teaching preparation and practices in special education. Email: yhsiao@tricity.wsu.edu

\section{REFERENCES}

American Educational Research Association, American psychological Association, \& National Council on Measurement in Education. (1999). Standards for educational and psychological testing. Washington, DC: American Educational Research Association.

Barnes, C. J. (2006). Preparing preservice teachers to teach in a culturally responsive way. Negro Educational Review, 57, 85-100.

Blanchett, W. J. (2006). Disproportionate representation of African American students in special education: Acknowledging the role of white privilege and racism. Educational Researcher, 35(6), 24-28.

Costello, A., \& Osborne, J. (2005). Best practices in exploratory factor analysis: Four recommendations for getting the most from your analysis. Practical Assessment, Research and Evaluation, 10(7). Retrieved from http://pareonline.net/pdf/v10n7.pdf

Field, A. (2009). Discovering Statistics Using SPSS. (3rd ed.). Los Angeles, CA: Sage.

Gay, G. (2002a). Culturally responsive teaching in special education for ethnically diverse students: Setting the stage. International Journal of Qualitative Studies in Education (QSE), 15, 613-629.

Gay, G. (2002b). Preparing for culturally responsive teaching. Journal of Teacher Education, 53, 106-116.

Gay, G. (2005). Politics of multicultural teacher education. Journal of Teacher Education, 56, 221-228.

Henson, R., \& Roberts, J. (2006). Use of exploratory factor analysis in published research: Common errors and some comment on improved practice. Educational and Psychological Measurement, 66, 393-416.

Hollins, E. R. (1993). Assessing teacher competence for diverse populations. Theory into Practice, 32, 93-99.

Irvine, J. J., \& Armento, B. J. (2001). Culturally responsive teaching: Lesson planning for elementary and middle grades. New York: McGraw-Hill.

National Council for Accreditation of Teacher Education. (2008). Professional standards for the accreditation of teacher preparation institutions. Retrieved from http://www.ncate.org/LinkClick.aspx?fileticket=nX43fwKc4Ak\%3D\&tabid=669

Pewewardy, C., \& Hammer, P. C. (2003). Culturally responsive teaching for American Indian students. WV: ERIC Clearinghouse on Rural Education and Small Schools Charleston. (ERIC Document Reproduction Service No. ED482325)

Plata, M. (2008). Cultural sensitivity: The basis for culturally relevant teaching. Teacher Education and Practice, $21,181-200$.

Rodriguez, Y. E., \& Sjostrom, B. R. (1996, February). Strategies for teaching in a culturally responsive manner. Paper presented at the Annual Meeting of the American Association of Colleges for Teacher Education, Chicago, IL. (ERIC Document Reproduction Service No. ED 394910)

Samuels, C. A. (2007). Minorities in special education studied by U.S. panel. Education Week, 27(15), 18-18.

Siwatu, K. O. (2006). The development of the culturally responsive teaching competencies: Implications for teacher education. Unpublished manuscript. 
Siwatu, K. O. (2007). Preservice teachers' culturally responsive teaching self-efficacy and outcome expectancy beliefs. Teaching and Teacher Education, 23, 1086-1101.

Spanierman, L. B., Oh, E., Heppner, P. P., Neville, H. A., Mobley, M., Wright, C. V., ...Navarro, R. (2011). The multicultural teaching competency scale: Development and initial validation. Urban Education, 46, 440464.

Stanley, L. S. (1996). The development and validation of an instrument to assess attitudes toward cultural diversity and pluralism among preservice physical educators. Educational and Psychological Measurement, 56, 891897.

Sue, D. W., Bernier, J. E., Durran, A., Feinberg, L., Pedersen, P., Smith, E. J., \& Vasquez-Nuttall, E. (1982). Position paper: Cross-cultural counseling competencies. The counseling Psychologist, 10(2), 45-52.

Wlodkowski, R. J. (1999). Motivation and diversity: A Frame for Teaching. New Directions for Teaching and Learning, 78, 7-16.

Worthington, R., \& Whittaker, T. (2006). Scale development research: A content analysis and recommendations for best practices. Counseling Psychologist, 34, 806-838. 


\section{NOTES}

